\title{
A encenação da violência: um exemplo no filme Cidade de Deus
}

Kati Eliana CaEtano Universidade Tuiuti do Paraná/UTP 


\section{Resumo}

O objetivo deste trabalho é examinar certos dispositivos e efeitos de presentificação dos sentidos sobre o destinatário na organização do discurso. Trata-se da análise de uma cena do filme brasileiro Cidade de Deus, considerada exemplar para a discussão teórica aqui proposta porque deflagradora de isotopias da violência cotidiana nas favelas brasileiras e, ao mesmo tempo, responsável pelas alterações do fluxo de atenção do espectador. Esse momento é visto como representativo, na medida em que metaforiza, do ponto de vista temático, o devir dos sujeitos desse microuniverso social e, da perspectiva da tensividade do texto, prenuncia acelerações virtuais no ritmo da narrativa filmica e na percepção do ouvinte, convertido em observador sensível dos acontecimentos.

\section{Palavras-chave}

cultura da mídia, enunciação, tensividade discursiva, violência, linguagem filmica

\section{Abstract}

This work analyses certain meaning effects of presence in relation to the addressee in the organization of the discourse. It is about one of the scenes of the Brazilian film City of God (Cidade de Deus) considered an example for the discussion proposed here because it creates isotopies of everyday violence in the Brazilian slums and, at the same time, is responsable for the enunciatee's attention flood alterations. As far as this moment creates metaphors as concerns the thematic point of view, it represents the coming of their social micto universe subjects and the text tensiveness perspective. It also advances virtual accelerations in the film's narrative rhythm and in the viewer's perception, who is converted into the sensitive observer of happenings.

\section{Key words}

media culture, enunciation, tensiveness, violence, film discourse 


\section{Introdução}

manifestação dos sentidos pode-se efetivar por processos
que envolvem tanto dispositivos da ordem do inteligível
quanto da ordem do sensivel. Pelas manobras do inteligível, nos são revelados temas, personagens, ações, que se projetam no tempo e no espaço, trazendo a sensação da temporalidade dos fatos, da espacialidade circunscrita a certos domínios e de sua inserção na memória. Pelo sensivel, tais mecanismos ganham sobredeterminações de natureza afetiva: o discurso não nos diz algo apenas, mas nos leva a sentir seus efeitos, a compartilhar sensorialmente dos estados emotivos presentes no nivel do enunciado, a acelerar o ritmo de nosso próprio corpo em consonância com o ritmo dos acontecimentos narrativos ou a distendê-lo em estado de êxtase ou serenidade quando assim se desenrola a trama discursiva.

Esses procedimentos ocorrem nos mais diversos tipos de textos, verbais, visuais, audiovisuais, e em suas diferentes modalidades, no texto jornalístico, televisivo, publicitário, filmico etc. Eles fazem parte, portanto, dos fenómenos que tocam o domínio da comunicação, na medida em que toda interação mobiliza recursos simbólicos que requerem tanto competências intelectivas quanto afetivas, gerando sintonias ou dessintonias aparentemente inexplicáveis, porque se situam no âmbito mais das emoções do que da razão.

A exploração do sensível nos textos é um dos recursos de presentificação do discurso nos vínculos estabelecidos entre destinadores e destinatários, que pode ocorrer por recursos multissensoriais, de efeitos de presença/ausência dos sujeitos 
discursivos ou de inflexões sobre a direção imprimida a um discurso, como ritmo, andamento, intensidade, entre outros. Esses últimos corresponderiam aos chamados traços segmentais dos discursos verbais (ritmo, tom, entonação, tonicidade) ou aos gradientes do discurso melódico, que dotam as composições das notas de efeitos especiais ao expressá-las, por exemplo, em adagio, allegro ou presto.

O objetivo deste trabalho é o de examinar um dos modos de presentificação da violência no filme Cidade de Deus, entendendo o discurso não só como o lugar de manifestação de conteúdos, mas também como o espaço de formalização de uma experiência sensível. $O$ foco está centrado em uma sequiênicia, considerada nuclear para a inserção patêmica do espectador no universo ficcional. Ao mesmo tempo que ganha sentidos específicos no contexto do filme, a cena escolhida projeta novas luzes à leitura da temática da violência nas periferias. Não se trata, portanto, de uma abordagem reducionista do filme, mas da análise de uma estratégia de encenação da experiência com a violência, vista da perspectiva de seus efeitos de sentido passionais numa cena exemplar.

Etapa final de um projeto de pesquisa sobre as vozes da periferia na mídia, o presente texto pretende expor, a partir de categorias da semiótica tensiva, de J. Fontanille e Cl. Zilberberg, além de noções extraídas dos estudós sociossemióticos de $\mathrm{E}$. Landowski, os mecanismos discursivos mobilizados para sensibilizar o espectadör diante de uma realidade várias vezes descrita e imaginada, mas que se pretende seja também vivenciada.

A pertinência das teorias mencionadas ao enfoque do objeto de estudo se deve ao fato de que, pela semiótica da presença, o sentido é analisado a partir de sua construção em ato, portanto na interação entre os integrantes do processo comunicativo, e, na semiótica tensiva, a narrativa é tomada em suas modulações organizacionais abordadas pelos efeitos que provoca sobre um observador sensível dos acontecimentos. Assim serão vistos tanto os personagens envolvidos na trama filmica, quanto o espectador "ideal" (em analogia ao conceito de leitor ideal de U. Eco), presumivelmente afetado, em sua sensibilidade corpórea, ao rumo e ritmo dos fatos que compõem a cena em questão. 


\section{A cena no filme}

O filme de Fernando Meirelles, adaptado do romance homônimo de Paulo Lins, terá aqui, portanto, uma abordagem metonímica, pelo exame de uma das cenas do filme, considerada pelo público (e também pela crítica) como "a mais chocante", e utilizada neste trabalho como um divisor de águas da sequiência fílmica. Divisor de águas tanto no sentido de instaurar dois momentos de interação do interlocutor com a trama da narrativa, quanto no fato de lhe permitir uma espécie de cumplicidade enunciativa com o narrador da história, que lhe impõe um sentir comum, por efeitos de deslocamento do ritmo ou do andamento do filme, do espaço e da temporalidade em que se insere.

$O$ discurso organiza-se em debreagem enunciativa, pois se trata da narração de um dos personagens sincretizado na figura đe um narrador em primeira pessoa. De sua perspectiva, a vida na periferia carioca da chamada Cidade de Deus é relatada, em fragmentos da cotidianidade, mas acompanhando os grupos que constituem o entorno do personagem desde $\mathbf{a}$ infầncia, passando pela adolescência até a juventude. É evidente que só de seu ponto de vista os fatos podem ser relatados, uma vez que o personagem/narrador fala de um outro espaço/tempo presente, em que consegue sair do mundo da favela e integrar-se ao stablishment, na concep̧̧ão de Norbert Elias. $O$ afastamento de uma situação vivida no espaço, em novas condições de vida e de valorização social, permite-lhe manter o olhar reflexivo diante do universo de sua descrição, que é aquele de sua vivência.

Tal condição do narrador inscreve, como corolário, a própria posição do enunciatário, que, embora sabendo de antemão tratar-se da representação de uma realidade assustadora, sente-se no espaço confortável de espectador, daquele que está do lado de cá da tela e que acompanha o percurso patêmico de um narrador em certo sentido também destacado dos acontecimentos. Em suma, há a consciência evidente de que se está ingressando na dimensão do discurso ficcional e que o representado constitui exatamente isso, uma represen-tação do que "foi" para o personagem que nos guia na leitura dos fatos. 
Um pouco à maneira do discurso machadiano, pode-se dizer que o enunciado cria no enunciatário expectativas ambíguas, uma vez que busca conhecer um mundo que teme, mas cujos mecanismos quer compreender, e o texto responde a esse afã com efeitos múltiplos de envolvimento afetivo e de recusa.

A cena nuclear deste trabalho expõe uma situação limite no contexto da trama. Visando a aplicar um corretivo nos "moleques do Caixa Baixa", que estavam saqueando o comércio local, e com isso desrespeitando as leis da favela (Eles precisam saber que a Cidade de Deus agora tinha dono) Zé Pequeno, um dos maiores líderes do tráfico local, obriga dois garotos a se confrontarem numa cena de morte. Depois de amedrontar duas crianças, aproximadamente de 7 e 10 anos, dando-lhes tiros nos pés, Zé Pequeno obriga Filé com Fritas a escolher um dos dois garotos para matar com um tiro. Filé com Fritas, adolescente, havia aparecido anteriormente no filme, primeiro de bracos dados com a mãe indo para a escola, depois entregando marmitas e fazendo pequenos serviços de compras para os adultos. Como está presente no grupo que assiste ao flagrante de Zé Pequeno contra as crianças e se afasta, evidențemente constrangido quando vê a cena dos tiros nos pés, o traficante o escolhe para atirar num dos garotos.

O horror da cena consiste não só na imposição do assassinato, mas também no fato de que envolve crianças para cumprirem tanto o papel do matador quanto das vítimas da ação de matar. Além disso, a imagem de Filé com Fritas nas cenas anteriores, fora da bandidagem, e a feição de descontentamento que manifesta diante da cena dos tiros, confere maior dramaticidade ao episódio, ressaltando o caráter patético da situação.

A manipulação de Zé Pequeno se faz por estratégias duplas, entre a tentação e a intimidação. Na semiótica discursiva, esses dois tipos de fazer persuasivo correspondem respectivamente à incitação pela modalidade do poder, positiva no primeiro (no caso, a sanção ao fazer do garoto que deve matar o qualificaria no mundo do crime) e negativa no segundo (ou se mata ou se morre). $O$ tumulto modopassional decorrente dessa determinação, entre o "não-querer" e o "saber não poder não matar" transforma o ritmo do filme colocando-o num outro "tempo" ou andamento. 


\section{A tensividade da cena}

Na semiótica tensiva, desenvolvida por Claude Zilberberg e Jacques Fontanille, o texto pode ser analisado por modulações tensivas que se desdobram em quatro sub-dimensões fundamentais: o "tempo" (andamento do texto), a intensidade, a temporalidade e a espacialidade. Cada uma dessas subdimensões se estruturam paradigmaticamente nas categorias: aceleração / lentidão; tonicidade / atonicidade ou intensidade / extensidade; tempo longo / breve e espaço aberto / fechado.

Para a presente investigação, interessam as projeções sobre o discurso de duas dessas estruturas paradigmáticas, a do andamento, que pode ser lento ou acelerado, e a da intensidade.

Pode-se dizer que o filme se desenvolve até a cena mencionada em seqüências rápidas, expondo fatos que atingem o espectador como rajadas de uma metralhadora. Já no início, assiste-se à perseguição de uma galinha, metáfora da perseguição policial que se consumará em seguida, precipitando o ritmo do filme para uma cena apoteótica que será retomada no desfecho da história. Esse direção imposta à sintaxe filmica propiciou várias aproximações do trabalho do diretor do filme, Fernando Meirelles, ao estilo do diretor norte-americano Quentin Tarantino, embora rejeitadas pelo cineasta brasileiro. No contexto dado, porém, a cena analisada opera o valor de uma transição de aceleração, a de um ritmo sentido pelo sujeito que sofre a ação (tanto a criança que mata quanto a que será morta) como mais rápido do que o vivido pelo seu corpo. Antes que sujeito do agir, pode-se falar nesse caso em sujeito agido, porque arrastado pelo turbilhão dos acontecimentos que o paralisam. Como afirma Landowski (1997, pp.115-116), a dimensão a ser examinada não é a de "uma temporalidade pura", mas a do "tempo vivido". Assiste-se, assim, a modos de concomitância divergentes na maneira de sentir o andamento dos acontecimentos para o sujeito: as expectativas dos garotos não se sincronizam às exigências đe Zé Pequeno, o que instaura uma relação de autoridade e medo, portanto de disforia, nas relações intersubjetivas, vividas pelos personagens. É dessa perspectiva que a situação dos garotos é apresentada, como um 
acontecimento da ordem do inesperado, ainda que vivenciado no olho da violência. Se de um lado se sabe que mais cedo ou mais tarde essa experiência deverá chegar, de outro, a condição de criança os coloca numa espera confiante, a de que tudo chegará no seu devido tempo, tanto as glórias quanto os riscos do banditismo (segundo um deles: "nóis tem que esperar os mais velho morrer depois nóis assume"). $O$ choque da ordem emanada pelos adultos, portanto, sobrevém pela surpresa diante da ação do outro (Zé Pequeno), muito além das expectativas do sujeito na sua situação presente de criança.

O estado atônito dos meninos encontra eco no relato do próprio narrador, enquanto personagem testemunha da experiência, a partir de quem se guia o olhar do espectador, supostamente surpreso diante de acontecimentos que não esperava. Conforme Zilberberg, para o que é sentido como rápido demais, não há espera, portanto a aceleração provoca o efeito daçuilo que ultrapassa ou supera todas as expectativas. A aceleração dos fatos, surgidos fora de um seqüenciamento previsivel, cria efeitos passionais que configuram a dramaticidade da situação. Nesse momento, o olhar fotográfico do narrador apontando para a violência se metaforiza na tomada do próprio cano do revólver apontando para a prática iminente do crime.

Os fatos se sucedem com muita rapidez, assim como a movimentação de câmera que oscila entre a fonte da ordem (Zé Pequeno) e os meninos apavorados. Embora tudo se passe praticamente num mesmo plano cinematográfico, o ritmo alucinante está formalizado nos. gritos, na movimentação rápida dos atores, na imprevisibilidade do desfecho (pergunta-se até que ponto Zé Pequeno está tripudiando sobre os meninos e de Filé com Fritas), o que garante uma espécie de suspensão momentânea do fôlego do espectador. Como explica Einsenstein em relação à filmagem da cena da escadaria de Odessa, no filme $O$ couraçado Potemkim, essa movimentação brusca, impondo ritmos distintos ao andamento dos fatos provoca uma alteração física do espectador que permite, com maior grau de presença, a sua inserção no domínio do patético.

A relação da aceleração à sub-dimensão da intensidade permite compreender melhor a força emotiva da cena. Como dizem 
Fontanille \& Zilberberg (2001, p. 19) "a intensidade e a extensidade são os funtivos de uma função que se poderia identificar como a tonicidade (tônico/átono), a intensidade à maneira da 'energia', que torna a percepção mais viva ou menos viva, e a extensidade à maneira das 'morfologias quantitativas' do mundo sensivel, que guiam ou condicionam o fluxo de atenção do sujeito da percepção." Os autores esquematizam tais relaçôes no seguinte esquema:

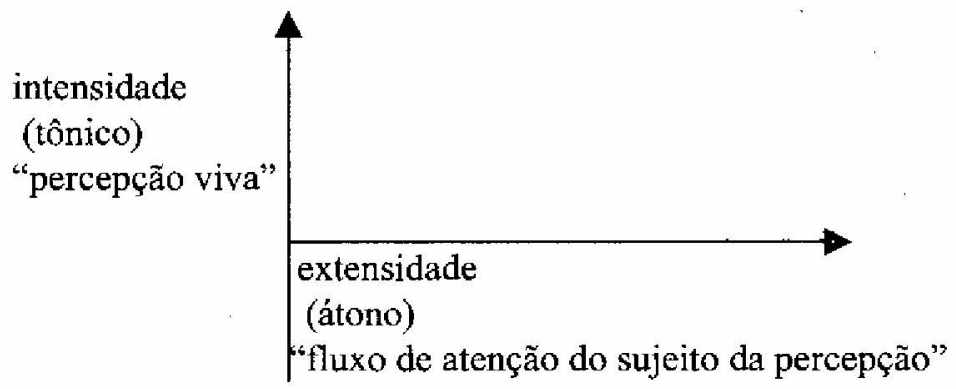

$\mathrm{O}$ andamento dos fatos determina nesse ponto dois modos de interação entre os envolvidos no mesmo quadro figurativo. $O$ valor ascendente da cena, sentida como uma aceleração do ritmo das coisas, da perspectiva tanto das crianças quanto do narrador, aparece como um momento de ruptura de toda a sequência, pontuada por forte emoção, o que permite inscrevê-la como uma manifestação intensa. Essa parada, ainda que rápida, atualiza o caráter excessivo da ordem imposta ao sujeito, e revela a impotencia do ser humano no sentido de encaminhar sua vida em outra direção. Aquele lugar e aquela hora parecem compor o cenário justificador para os móveis de toda a violência, e o batismo de fogo para a entrada num mundo em que os valores éticos e morais vão se forjando de acordo com o poder instituido hic et nunc. Dominado pelo excessivo, surpreendido pela rapidez com que se sente confrontado ao desejo do outro e movido pelo terror intenso, Filé com Fritas acaba cometendo o assassinato do garoto. $\mathrm{Na}$ seqüencia, a cena se modifica, com a recuperação da estabilidade anterior, mesmo que para situar a partir daí a regularidade das instabilidades e a necessária qualificação do indivíduo para enfrentar o impossível e inimaginável. Não é por acaso 
que Filé com Fritas aparece posteriormente, na terceira parte do filme, pedindo para entrar nos bandos que pretendem matar Zé Pequeno. O personagem dessa parte está claramente diferente do início, sente-se um amadurecimento obtido à força e confirma-se a suposição primeira, de que a cena do assassinato se apresentava como uma revelação da gênese da bandidagem. Na verdade, o que se manifesta na mudança de Filé com Fritas é o devir de todos os outros garotos desse microuniverso social, que se anuncia reiteradamente. (Landowski, 1997, p. 124.)

A integração da cena no contexto global do filme permite, assim, melhor compreender sua função desencadeadora de isotopias. O filme é circular, não só pela estrutura de desenvolvimento da história, que se inicia com a cena final, mas também pela recorrência de personagens e situações, cujas condutas vão sendo justificadas ou contextualizadas ao longo do filme. Nesse sentido, fica evidente a demarcação dada pela cena, que acontece quase na metade do filme, prenunciando o destino de Filé com Fritas e alinhavando o desfecho trágico de Zé Pequeno, morto pelos próprios garotos. Os fragmentos da vida na favela, a seqüência de fatos aparentemente sem ligação, tomam sentido quando se refaz a leitura do filme encarando a cena dos meninos como a revelação de um ritual da violência que constitui o cenário em que nascem, crescem e morrem os filhos dessa sociedade. Não é por acaso que o único personagem a ficar fora desse ambiente, ainda que mergulhado na sua cotidianidade, é o narrador, cuja ação pragmática consiste em mostrar fotograficamente a violência. (Assim como se vê nos cantores de rap, nos poetas da chamada cultura da periferia, em que a violência é resultado de um fazer cognitivo que se manifesta por via poética)

Projetando os valores no mesmo esquema anterior, têm-se os dois eixos assim caracterizados pela intensidade, tempo breve e andamento acelerado na coluna vertical e extensidade, tempo longo e menos acelerado na coluna horizontal. A passagem da direita para a esquerda mostra a ruptura afetiva provocada pela cena sobre a sensibilidade dos sujeitos e o percurso inverso, da esquerda para a direita, caracteriza a finalização da cena e a retomada da estabilidade narrativa: 


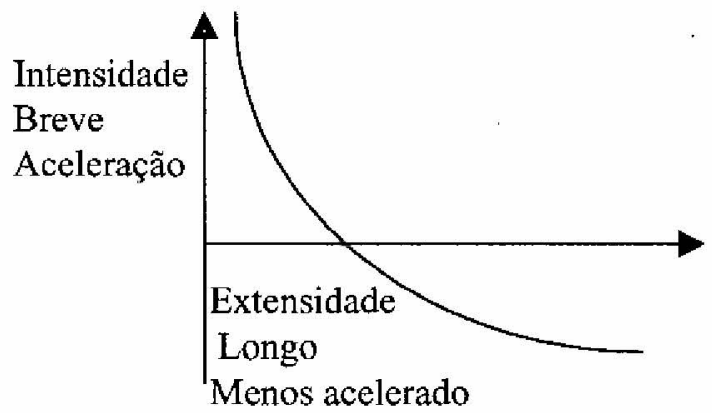

Esses gradientes devem ser analisados sempre em suas posições relacionais, quando podem ser focalizados nos contextos particulares em que se inserem. Apenas dessa perspectiva é possível afirmar o caráter excessivo da cena como condicionante da insuficiência do restante do filme, a aceleração em contraste com a lentiđão e a brevidade em oposição à longevidade.

Deve-se compreender ainda que, se de um lado a cena em exame é intensa, de outro, seu efeito prolonga-se na extensidade, porque é por meio dela que se instala a cumplicidade na aceitação dos fatos posteriores, seja no nível narrativo, pelos personagens envolvidos na trama, seja no nível enunciativo, pela antecipação passionalizada do que representa o devir dessas crianças. Os mesmos efeitos reconhecíveis no nível narrativo são homologados, por conseguinte, no nível da discursividade.

Assim, a cena em que Filé com Fritas é obrigado a matar outra criança repercute também sobre o olhar do enunciatário, posicionado na condição de mero espectador dos problemas sociais. Embora se situando desde o primeiro momento, graças ao conhecimento pragmático, em dois universos diferentes, e atribuindo aos sujeitos narrativos o caráter de "estrangeiros" em sua própria terra, tanto pelo fato de serem construções discursivas, ficcionais, quanto pelo seus modos de ser/agir, o espectador é induzido, pela primeira vez no filme, a uma espécie de grau zero de moralidade. $O$ que sobrevém com a cena emn questão ultrapassa os limites do esperado em termos de violência, e, como toda imagem-choque, visa a levar à conscientização pelo impacto. 
A partir daí, uma nova competência é exigida no âmbito do fazer interpretativo, que não pode se limitar mais à visualização de uma encenação da violência, mas à sua presentificação, com efeitos de compartilhamento dos sentidos e das sensações. De acordo com essa reflexão, opera-se um duplo deslocamento, o da criança que sai do mundo da infância para iniciar-se definitivamente no mundo do crime, estigma de sua condição social, e $\odot$ do observador sensível que vê reduzido o espaço que o separa da simulação na tela para sentir "ao vivo" o fato referenciado.

Para Zilberberg \& Fontanille (Op. cit., p. 124), uma existência semiótica define-se como presença quando se constitui como "um objeto de saber para um sujeito cognitivo". É esse saber que o filme revela, tentando inscrever o espectador como o sujeito cognitivo capaz de compreender o movimento social em que ele próprio se insere. A questão da presença na dêixis espacial implica a mudança da configuração do objeto com respeito à posição do sujeito cognitivo, que, de distante, passa a se situar mais próximo do seu alcance pela conversão de uma presença virtualizada em presença realizada.

Assim como os atores da narrativa retomam um outro "tempo" na seqüência do filme, o observador sensível (sincretizado na figura do narrador-personagem que assume uma voz coletiva) toma consciência de que tudo pode advir a partir dali, o impossível e o inimaginável. Para o espectador do filme só resta a opção de ficar ou sair da sala, do que pode depender a anulação de sua própria coṇição de espectador, pois mergulhar no filme significa impregnar-se, de um ponto de vista amoral, num espaço/tempo de outros valores, num ritmo de paixões intensas e disfóricas. Tal qual o personagem de Cortázar, no conto A.continuidade dos parques, que, segundo Greimas (2002), anuncia a morte do leitor ao imergir na: leitura do texto, sentindo os diálogos dos amantes como "um riacho de serpentes", espera-se que o espectador do filme vivencie o apagamento de sua presença diante da cena quando se flagra constatando que isso é a realidade de que ele participa. Retomando afirmação de Landowski (embora aplicada a outro propósito), o que se pretende aqui é a sensação não só de que existimos, mas sobretudo de nos vermos existir (1997, p.126). Entende-se agora porque a maior parte das críticas 
especializadas dirigidas ao filme referem-se não só à violência dessa parte, mas ao critério de realidade estabelecido, esquecendo-se que, na qualidade de ficção, não se trata mais de perguntar se os fatos aconteceram ou não.

Talvez seja interessante observar que a cena não se destaca no livro, mas ali está presente uma outra, igualmente intensa, que não foi registrada em filme. Trata-se do assassinato de um bebê com requintes de crueldade. A tônica da passagem, no entanto, não está na aceleração do andamento, e sim no prolongamento, na lentidão da narrativa, que se esmera em detalhes insuportáveis. Representá-la no filme seria evidenciar uma intenção que provavelmente manteria distantes os papéis discursivos acima apontados, o que leva a concluir pela competência da direção cinematográfica nesse caso.

\section{Considerações finais}

Configuram-se nessa sequiência as práticas ou situações em que a gênese da violência aparece explicitada, sob a forma de condicionantes da impotência do sujeito para a recusa dos valores que a manifestam. Nesse caso, como em outras manifestaçôes recentes da periferia, o sujeito escapa pelo fazer artístico. Aqui, porém, não se fala sobre a violência; espera-se que ela seja sentida pelo espectador por meio de estratégias enunciativas diversas, de que resulta o apagamento da oposição "nós x eles" e a presentificação de uma realidade vivida e vivenciada por todos. Ent suma, o recurso utilizado é o da reconstrução desse cenário para o espectador, que se torna o observador sensível, pelo fato de sentir a partir do corpo próprio, a realidade em que vivem os personagens da estória, pela ótica de um narrador/protagonista.

Mais do que imprimir um novo ritmo a um fato isolado, no entanto, a cena considerada introduz a expectativa de um ritmo de acelerações virtuais ao fluxo do tempo. Estar alerta para tais alterações rítmicas, provocadas pela ação dos acontecimentos sobre a frágil condição humana, indica a capacidade reflexiva para compreender e vivenciar a vida em perigo. 
Não há dúvida de que a exposição constante desses tipos de imagens deriva para a banalização dos seus investimentos semânticos, e, por conseguinte, ao amortecimento dos sentidos, mas é preciso considerar o outro lado da moeda: o de que talvez necessitemos de sua redifusão, em contextos específicos e por meio de estratégias de sensibilização, a fim de nos lembrar, como diz Susan Sontag, que coisas terríveis acontecem e que perdemos a sensibilidade de retêlas na nossa mente.

\section{Bibliografia}

ELIAS, N. \& SCOTSON, J.L. 2000. Os estabelecidos e os outsiders. Rio de Janeiro: Jorge Zahar Ed.

ENZENSBERGER, H.M. 2001. Paranóia da autodestruição. Caderno Mais. Folha de São Paulo, 11/11, p. 5-7.

FONTANILLE, J. \& ZILBERBERG, C. 2001. Tensão e significa. ção. São Paulo: Discurso Editorial//Humanitas/FFLCH/USP. Além 'dessa obra, foram utilizadas, no presente texto, noções teóricas desses autores expostas em seminários realizados na França e no Brasil.

GREIMAS, A. J. 1975. Sobre o sentido. Petrópolis: Vozes. . Da imperfeição. 2002. São Paulo: Hacker Editores'.

GREIMAS, A.J. \& COURTÈS, J. 1979. Dicionário de semiótica. São Paulo: Cultrix.

GREIMAS, A. J. \& FONTANILLE, J. 1991. Sémiotique des passions: des états de choses aux états d'âme. Paris: Seuil.

LANDOWSKI, E. 1992. A sociedade refletida. São Paulo: EDUC/ Pontes.

1997. Présences de l'autre: essais de socio-sémiotique II. Paris: Presses Universitaires de France.

PUAUX, F. (org.). 1999. La marginalité à l' écran. Revista CinémAction. France: Corlet - Télérama, n.91.

SONTAG, S. 2003, Diante da dor dos outros. São Paulo: Companhia das Letras.

VIANNA, H. 1997. Galeras cariocas: territórios de conflitos e encontros culturais. Rio de Janeiro: UFRJ. 